\title{
A força tanática na poesia de Nuno Júdice
}

Egidia Souto

Universidade Sorbonne-Nouvelle Paris 3

\begin{abstract}
Ideia da morte
O anjo da morte, que em certas lendas se chama Samael, e do qual se conta que o próprio Moisés teve de o afrontar, é a linguagem. $O$ anjo anuncia-nos a morte - e que outra coisa faz a linguagem? - mas é precisamente esse anúncio que torna a morte tão difícil para nós. Desde tempos imemoriais, desde que tem história, a humanidade luta com o anjo para lhe arrancar o segredo que ele se limita a anunciar. Mas das suas mãos pueris apenas se pode arrancar aquele anúncio que ele nos viera fazer. $\mathrm{O}$ anjo não tem culpa disso, e só quem compreende a inocência da linguagem entende também o verdadeiro sentido desse anúncio e pode, eventualmente, aprender a morrer.
\end{abstract}

Giorgio Agamben, Ideia da Prosa

ste tema é sem dúvida o mais complexo em toda a obra judiciana, pois, para além de carregar o valor trágico da palavra, tem múltiplas significações e atravessa quarenta anos de obra poética. Ao longo destas breves páginas tentaremos demonstrar a obsessão do autor pela figura da morte, uma vez que nem sempre está associada ao luto e à tristeza porque ela é, de certa forma, a origem da própria linguagem.

O texto com o qual introduzimos a nossa temática é pertinente na medida em que Giorgio Agamben relaciona a morte com a linguagem, e é precisamente isso que Nuno Júdice 
faz. Neste excerto, o autor lança uma questão chave: "O anjo anuncia-nos a morte - e que outra coisa faz a linguagem?". Nuno Júdice, que tanto se debruçou sobre a teorização da poesia e das artes poéticas, descreve por diversas vezes a morte como uma forma de vida, no sentido em que esta funciona como contra-relógio obrigando o sujeito a escrever de forma incessante, lutando assim pela absolvição. Outra analogia é a ausência de rosto quer da morte quer da linguagem. No ensaio Máscaras do Poema, Nuno Júdice, no capítulo sobre "As linguagens e as máscaras do poema" demonstra bem essa analogia:

(...) a linguagem não tem nunca um rosto definitivo, quer seja o sujeito que inventa esse ser, a quem chamamos Autor (...). É preciso, antes de mais, descobrir esse sujeito no interior de nós próprios - e, depois disso, tentar encontrar uma forma de o fazer falar, o que sucede de cada vez que se escreve e que se encontra, no que escrevemos, a presença desse outro que se manifesta através de palavras. ${ }^{1}$

Como vimos, o autor tenta encontrar um rosto para a linguagem, materializando-o para que esta deixe de ser um fantasma, o mesmo acontece com a figura da morte. E o Eulírico tem consciência de que evocá-la é essencialmente o que faz viver, embora esta ideia seja paradoxal. No entanto, ele personifica-a de tal modo que esta força é capaz de o levar ao estado de nirvana, ou seja à condição de libertação do sofrimento. Como defendia Heidegger, só perante a morte é que a vida se elucida. Tentando apagar a figura da morte, o ser humano mergulha no que o filósofo chama de existência inautêntica; ora, pensar a morte, permite pensar a vida e, desta feita, viver uma existência autêntica e profunda e num estado de felicidade. Assim sendo, a presença da morte é o que torna autêntico o ser

${ }^{1}$ JÚDICE, 1998. 
humano. Esta traz ao poeta a anunciação das trevas em oposição à "presença divina" do mundo, quer dizer, é ela a personificação do caos primordial. Veja-se este tema de índole romântica por excelência como uma fractura ambígua na poesia judiciana. Por um lado, a imagem da morte surge como uma figura que no pensamento medieval representa o medo e o fim, e por outro, apresenta-se como sedutora e fascinante a tal ponto humanizada que os românticos se apaixonam por esta figura que se metamorfoseia no alvo dos desejos íntimos de cada um. Já não se trata de um anacronismo religioso mas sim de um desejo de imortalidade. Para Eduardo Lourenço:

A morte - espaço da morte - é como o antigo espaço de Deus (ou a sua sombra): está em toda a parte, penetra tudo, corrompe tudo, não começa para lá do nosso fim sensível, não parece abrir para qualquer coisa de oposto, digamos, um verdadeiro além vencedor da morte. A "sua" morte é já, como dirá mais tarde Pessoa da noite "a substância natural de todas as coisas. ${ }^{2}$

Nuno Júdice abordou esta ideia de que a morte pode ser vencida através da memória no ensaio Máscaras do Poema procurando afastar o medo do esquecimento. Se o espaço da morte aproxima de Deus, como defende Eduardo Lourenço, a memória só pode ser guardada através da palavra, como reitera ainda o filósofo: "(...) Este é, então, o plano da anti-utopia: aquele em que o homem tomando consciência da sua condição de mortal, procura a sua sobrevivência que é, acima de tudo, a permanência na memória que só existe na palavra que lhe dá forma. ${ }^{\prime 3}$

2 LOURENÇO, 2007.

${ }^{3}$ LOURENÇO, 2007. 
De facto, ao longo de quase 40 obras, sejam elas poéticas ou em prosa, a morte está sempre presente: o simples facto de escrever sobre ela, de lhe dar um rosto não será uma forma de combater o medo de morrer? Os primeiros livros, e mais concretamente até Lira de Líquen (1986), são os que mais refletem essa preocupação com o lado noturno do ser. Os poemas evocam, com uma certa obsessão, uma dependência das imagens e inerente a elas há um vasto léxico que nos conduz para o mundo fúnebre num registo próximo do que Gilbert Durand designa de "regime noturno das imagens": "noite"; "nocturno"; "névoa"; "sombras"; "fúnebre"; "campa"; "cemitério"; "terra negra"; "fénix"; "pó"; "alma"; "túmulo"; "coveiro"; "obscura"; "sinistro"; "limbo" são alguns dos nomes e adjetivos que nos remetem para este mundo. Mas há também uma grande exploração da noção de decadência que conduz à morte e que veremos mais adiante. A morte, figura retórica dominante, alimenta a máquina do teatro, tornando-se uma alegoria da transgressão. E se este é o tema romântico por excelência, é de igual modo barroco, no sentido em que vai além-túmulo, põe em cena a degenerescência física a fim de obter efeitos figurativos e dramáticos. Abordando os grandes temas da humanidade, tais como: amor, morte, solidão, nostalgia, o sujeito lírico vive o drama de um tempo fracturado e reflete nos poemas o estado do mundo. Não esqueçamos que Nos Braços da Exígua Luz data de 1976, pouco depois do 25 de Abril. Estamos ainda perante um período de opressão, pois o país acaba de sair da ditadura e os poemas expressam ainda as algemas e a asfixia do regime salazarista. Numa entrevista em que responde sobre a questão da morte, o autor menciona que: "A morte tem a ver com a época dos anos 60 até 1974, ela dirse-ia uma figura metafórica do país, visualizado na imagem cemiterial". 
Todavia, mais do que uma imagem do país, a morte parece-nos ser para o autor uma forma de exorcizar os medos da infância, o terror do Inferno, as leituras de Dante, o medo de um fim sem palavras. Numa atitude eufemizadora, Nuno Júdice faz da morte uma figura feminina de grande poder. Esta aparece ao poeta como se fosse um vulto de sombra e está sempre ligada ao universo da noite. Assim sendo, intensificalhe os medos e obriga-o a enfrentar os fantasmas. Desta forma, a morte possibilita o confronto, e desse confronto nasce a poesia. No seguinte poema, o choque com a morte é exposto de uma forma concreta; o poema funciona como um diário:

Eu vi a morte, num fim de dia, entre pálios vazios, cibórios, pendões de uma velha confraria hasteados nas noites de velórios: e ela tocou-me com os frios dedos, indecisa, puxando-me para si - lembrou-me esquecidos medos, outonos, sonos que não dormi.

(Lira de Líquen, p. 287)

Repare-se que aqui a morte surge num cenário propício, "num fim de tarde", talvez perto do crepúsculo, no meio de uma procissão de velório. Ela é a figura central do pálio, a única que, por entre os santos e as hastes, está viva: isto porque o poeta a vê, mas também porque a torna real. Ela é a personificação do medo mas também mulher capaz (veja-se os verbos de movimento que o poeta emprega "tocar", "puxar"), de suscitar outras lembranças passadas: "ela tocou-me com os frios dedos". Neste verso, o toque da morte é erotizado pelo facto de pressupor uma cumplicidade antiga entre os dois: uma relação de predador e presa: "indecisa, puxando-me para si / lembrou-me esquecidos medos (...)". O ato de puxar o sujeito e lembrar-lhe o passado faz dele um ser vulnerável perante a morte. Nada no poema nos mostra que ele não a aceite ou que lute contra esta força maléfica que o Eu deseja. 
Parece-nos que a cumplicidade da morte é também a relação com as palavras: há um jogo melodramático com a figura com que cria um teatro misterioso e de índole simbolista. Nuno Júdice deixa transparecer um intenso sentimento dramático coadunado com uma forte raiz simbolista na poesia dos anos 90. Com efeito, o poeta bebeu, também nas fontes da arte e da literatura barroca que têm um fundo ligado ao neo-platonismo e que revelam um lado esotérico, misterioso, mórbido, obscuro e também profundamente erótico. Temas esses igualmente abordados pelos românticos, na linha a que Mário Praz veio a chamar de romantismo negro. Não esqueçamos ainda a importância da pintura na poesia de Nuno Júdice. Pensamos nomeadamente no quadro que figura no livro O Anjo da tempestade (2004), de Antoine Wiertz, Deux jeunes filles, ou la belle Rosine (1847), em que a figura da morte erotizada oscila entre o carnal e o espiritual. Ainda desta primeira fase mais noturna atente-se neste poema que pelo título nos remete para uma lápide funerária.

\section{Inscrito}

Mas os olhos fechados. Toda a pouca importância de essa morte aqui. Também aqueles que o disseram

não sobreviverão às palavras pronunciadas que (elas sim!) prolongam este gesto - poético! - o poema insuportável morte criação de dedos no vazio do corpo, do copo a brusca meditação cortada.

Ó terra: fala a voz de raízes doces na concavidade da tarde o conhecimento fúnebre um rigor no crescimento na composição num cálculo de puro mover-se a descida para o chão pó

o que fica. 
Este poema enfatiza a visão do mundo trágico e condenado, todavia as palavras prolongam a vida e, apesar da condenação, o poeta tem ainda a ilusão e uma esperança sólida no que diz respeito ao renascimento: a poesia, a vida e a morte estão inteiramente ligadas. O poema apresenta uma sintaxe que estrutura a semântica de forma muito expressiva, havendo uma certa desorganização nos versos, e o primeiro verso "os olhos fechados" remete-nos para o mundo do sonho, do sono como se o poeta adivinhasse a morte e o caos. No entanto, esse estado de sonho é doloroso: "o poema insuportável morte/ criação de dedos no vazio do corpo, do copo (...)". A morte é um mal necessário que leva o sujeito a implorar à terra para que esta fale, ou melhor para que se renove.

Morremos e renascemos todos os dias; o corpo sofre a regeneração celular; procuramos sem cessar a pequena morte, a libertação de uma pressão terrena. A morte existe porque existe a vida, e, pelo meio, a poesia vai permitindo ao autor aceder a estados de clarividência. Aos poucos, os poemas vão sendo menos negros, a figura macabra da morte vai-se dissipando e dando lugar a um semblante mais ténue e humano. O poeta está conciliado com a ideia da morte, isto porque aprendeu a combatê-la com a linguagem, morre e volta a renascer em cada novo poema aceitando assim o ciclo da vida. Pois, para Nuno Júdice, o mundo tem de estar em harmonia, e para isso, é preciso alinhar todos os elementos. Apesar de a poesia do autor ser fortemente marcada pela figura da morte, Nuno Júdice mostra que esta faz parte da vida, pois morte e vida estão intimamente ligadas: uma precisa da outra para existir. É o princípio da metamorfose que alimenta a máquina da literatura. Em 2005, numa entrevista, ele próprio o diz: "esgotei a minha relação com o tema vida e morte". Embora a morte não esteja tão presente nos últimos livros ela espreita incessantemente, algures "num beco de Samarcanda". Uns dos mais recentes livros, Guia dos Conceitos Básicos (2010), traduz a 
força dessa imagem que surge no entanto mais "apprivoisé" e bastante irónica. Já não é a figura romântica exaltada que vimos com os poemas de Lira de Líquen ou Nos Braços da Exígua Luz mas sim um alter-ego, digamos, das próprias preocupações do Eupoético. Leia-se o poema "O chá de Samarcanda":

Num beco de Samarcanda encontrei-me com a morte. Olhou para mim como se não me visse. Fui ter com ela e perguntei-lhe se estava à minha espera. Mas ela virou-se para o outro lado, atravessou a rua, e perdia de vista. (...)

(Guia de Conceitos Básicos, p. 57)

Neste poema com muito humor e ironia o eu poético convida a morte para beber chá de menta. Vemos na primeira estrofe que o confronto é abordado desde logo, pois o poema inicia-se com um jogo de sedução neste encontro/desencontro entre Eros e Thanatos. A morte simplesmente ignora quem a quer encontrar. "Fui ter com ela e perguntei-lhe/se estava à minha espera." Este verso irónico, denota claramente uma lucidez perante o fim que espera todos os mortais. Já na terceira e última estrofe, longe da imagem de ceifeira, o sujeito teima em reunir-se com esta força que o ignorou. Em suma, a morte serve de pretexto para que se pense no que poderia ter acontecido caso esta não tivesse atravessado a estrada:

Ou pode ser que Samarcanda não seja o sítio melhor para encontrar a morte, e para a morte me encontrar. Então, dir-lhe-ei: vamos

a uma loja de tapetes, e embarquemos num deles para o outro lado do mundo, onde o nosso encontro se faça.

Mas a morte dir-me-á que o outro lado do mundo é demasiado longe. A morte 
já andou muito para encontrar quem tinha de encontrar (....).

(Guia de Conceitos Básicos, p. 58)

Neste poema, quase um monólogo, é-nos dado a ler a história do desencontro e do destino que está traçado para cada um de nós mortais. A poesia confunde-se com a vida. É uma forte imagem de morte personificada que nos conduz para a viagem e a eternidade. E aqui temos novamente a dualidade: se nos reportarmos ao discurso mitológico, a morte, de facto, «ne serait pas le dernier voyage. Elle serait le premier voyage», como nos diz Bachelard. ${ }^{4}$ Através da referência à "loja de tapetes" não procurará o poeta constantemente encetar a viagem eterna, que segundo a psicanálise estaria na base do trabalho humano? O verbo "embarcar" seguido de para "o outro lado do mundo" acentua esse desejo de evasão realçado pela presença do tapete mágico voador. Não será este uma evocação do lendário tapete das Mil e Uma Noites? Parece-nos ainda que a morte está cansada e já não cumpre ordens, como se pode ler na última estrofe. A leitura deste poema leva-nos a pensar num outro aspecto extremamente original da poesia de Nuno Júdice: a intertextualidade e a relação inter-artes que o poeta estabelece ao longo de inúmeras obras. Diríamos deste modo que este poema evoca o filme de Fritz Lang (1921) "A morte cansada" e também nos parece que poderia ser, ainda que discretamente, uma bela homenagem a José Saramago e ao seu livro As intermitências da Morte, livro esse que personifica a morte também ela cansada das suas atividades. Tal como no livro de Saramago, também na poesia de Nuno Júdice a morte passa a ter duas faces, a que ceifa a vida e a que tem agora braços de mulher. Longe de ser uma sombra sem corpo, a morte,

${ }^{4}$ BACHELARD, 1972. 
como nos sugere o poema "Episódio de café", é feminina como se pode ler nos versos: "sentou-se à minha frente uma rapariga vestida de preto que,/ por me lembrar a imagem da morte, me fez levantar e/ sair do café, (...)". Terminemos no entanto a leitura do poema com a última estrofe:

(...) "Por que está vestida de preto?". Mas

ela já não me ouviu; e quando atravessou a rua, e começou a passar a ponte do châtelet, eu é que corri atrás dela, para confirmar

se era a morte, ou se apenas se vestira de preto para me obrigar

a esquecer-me dos livros, e para poder dizer, hoje, que a morte correu atrás de mim para me libertar da sua imagem."

(Guia de Conceitos Básicos, p. 58)

Também neste poema a morte atravessa a rua sem ceifar a vida de quem quer que fosse. Mostra assim que afinal mesmo a morte pode apresentar humanidade e acima de tudo ser uma "libertação". Lautréamont lembrava que "Não se pode julgar a beleza da morte senão pela da vida".

Para concluir afirmaríamos que a poesia de Nuno Júdice detecta as linhas de força dessa imagem da morte que a metamorfose do sujeito e dos objetos procura libertar da sua negatividade. A morte é talvez uma das principais forças desta poesia que faz com que cada leitor procure através do poema uma dimensão espiritual. A morte é uma espécie de dom que faz com que o poeta veja não o fim mas sim o princípio. Por essa razão, a morte que tanto assombra Nuno Júdice e que nos pode, enquanto leitores, causar repugnância é mais uma questão filosófica e metafísica. Os poemas já não são o que Joaquim Manuel Magalhães designa de "baladas lúgubres" mas sim episódios esporádicos como este em que vida e morte se confundem algures num café do mundo. 


\section{Referências}

AMARAL, Fernando Pinto do. Nuno Júdice: entre a ironia e a analogia. In: . O mosaico fluido - Modernidade e Pós-modernidade na poesia portuguesa mais recente. Lisboa: Assírio \& Alvim, 1991. p. 80-93. ALVES, Ida. Nuno Júdice: Arte poética com melancolia. Boletim de Pesquisa NELIC, Ilha de Santa Catarina: UFSC, v. 8/9, p. 112-10, 2006. ARIÈS, Phillippe. Essais sur l'histoire de la mort en Occident du Moyen Âge à nos jours. Paris: Seuil, 1975.

AGAMBEN, Giorgio. Ideia da Prosa. Lisboa: Cotovia, 1999.

BACHELARD, Gaston. L'eau et les rêves, [essai sur l'imagination et la matière]. Paris: José Corti, 1972.

CARVALHO, José Carlos. Dizer o amor é fundamental para que ele se realize. Diário de Notícias, terça-feira, 12 de abril, 2005.

DURAND, Gilbert. L'imagination symbolique. Paris: PUF, 1993.

GASTÃO, Ana Marques. Enigma para cercar o mundo. Diário de Notícias, Lisboa, 25 dez. 2000.

HEIDEGGER, Martin. Être et le Temps. Paris: Gallimard, 1986.

JÚDICE, Nuno. Máscaras do Poema. Lisboa: Aríon Publicações, 1998.

JÚDICE, Nuno. Poesia Reunida 1967-2000. Lisboa: D. Quixote, 2000.

JÚDICE, Nuno. Guia dos Conceitos Básicos. Lisboa: Dom Quixote, 2010.

LOURENÇO, Eduardo. A morte, de Schopenhauer a Unamuno. Jornal de Letras Artes e Ideias, 29 de agosto-11 de setembro 2007.

LAUTRÉAMONT. Cantos de Maldoror. Lisboa: Fenda Edições, 1988.

MAGALHÃES, Joaquim Manuel de. Nuno Júdice. In: Um pouco da morte. Lisboa: Ed. Presença, 1989, p. 247-252.

PRAZ, Mário. La chair, la morte et le diable dans la littérature du XIX, le romantisme noir. Paris: Gallimard, 1998.

SARAMAGO José. As intermitências da Morte. Porto: Asa, 2005. 


\section{Resumo}

Para Nuno Júdice a morte que o persegue a ele e a nós leitores é o medo do fim. No entanto, o poeta não conhece o fim porque está em osmose com todos os elementos e, associado à morte está a água, elemento de vida por excelência. E por mais pútrido que seja o cenário, os sujeitos criados por Nuno Júdice são sempre capazes de ressurgir das cinzas, da putrefacção e até de ver na morte a libertação. Apesar de a poesia do autor ser fortemente marcada pela figura da morte, ele mostra que esta faz parte da vida, pois morte e vida estão intimamente ligadas: uma precisa da outra para existir. Pretendemos demonstrar que para o poeta na morte há mais do que o vazio, há vida e caos e as palavras vão para além de simples significantes; elas são imagens vivas que desfilam no filme que Nuno Júdice projeta ao longo dos seus poemas. Desde os anos 90, o autor retomou o classicismo e a morte é menos recorrente. Parece ter havido uma reconciliação com as trevas.

\section{Résumé}

Pour Nuno Júdice la mort qui le poursuit à lui-même et à nous lecteurs, c'est la peur de la fin. Cependant, le poète ne connaît pas la fin dans la mesure où il est en osmose avec tous les éléments et, associée à la mort il y a l'eau, élément de vie par excellence. Ainsi, pour plus que le décor soit putride, les hommes créés par Nuno Júdice sont toujours capables de revenir des cendres, de la putréfaction et de voir dans la mort la libération. Même si la poésie de l'auteur est fortement marquée par la figure de la mort. Il démontre qu'elle fait partie de la vie, puisque mort et vie sont intimement liées, l'une à besoin de l'autre pour exister. Nous voulons démontrer que pour le poète il y a bien plus dans la figure de la mort que le vide, il y a la vie et le chaos 
et les mots vont au-delà des simples signifiants; ils sont des images vivantes qui se défilent dans le film que Nuno Júdice projette au long de ses poèmes. Depuis les années 90, l'auteur s'est retourné vers le classicisme et la mort et moins récurrente. Il semble y avoir eu une réconciliation. 